\title{
The choice of period when estimating loading on cylinders from regular waves
}

\section{R. BURROWS}

\section{Dr T. L. Shaw, M}

The Paper leaves open the essential question of selecting from typical wave spectra, at the intended site for construction, that wave or short sequence which will impose on each member the force having the appropriate probability of return. Can the Author give any guidance on this?

\section{Mr Burrows}

Dr Shaw rightly points out the importance of a precise knowledge of the probability of return of any wave load prediction in the design of structures exposed to random ocean waves. However, this question is outside the scope of the Paper which was intended primarily as an aid to the engineer involved in deterministic, design wave analysis where the probability of return of the wave height has been accepted as the design criterion.

23. As wave load is a function of both wave height $H$ and period $T$, loading of predetermined probability of return cannot be ascertained directly from a wave profile defined by a chosen $(H, T)$ pair. Moreover, in view of the behaviour shown in the Paper there seems little reason to expect such a wave profile to produce, on all members submerged beneath it, loads with the same probability of return.

24. Dr Shaw's problem of associating member loading to probability of occurrence can be solved using fully probabilistic methods such as those developed at the University of Liverpool. ${ }^{4-6}$

\section{References}

4. Holmes P. et al. Prediction of long-term wave loading on offshore structures. Department of Civil Engineering, University of Liverpool, 1975, Report on Section A of Offshore Structures Fluid Loading Advisory Group Project 5.

5. Tickell R. G. et al. Long-term wave loading on offshore structures. Proc. Insin Civ. Engrs, Part 2, 1976, 61, Mar., 145-162.

6. Burrows R. A simple technique for the prediction of non-linear random wave loading. Proc. Insin Civ. Engrs, Part 2, 1978, 65, Dec., 731-747. 